\title{
Qualidade microbiológica e físico-química de sorvetes sabor chocolate comercializados na cidade de Limoeiro do Norte, Ceará, Brasil
}

\author{
Samuel Carneiro de Barcelos ${ }^{1}$, Edilene Ferreira da Silva ${ }^{2}$, Elisabeth Mariano Batista ${ }^{3}$, Sandra \\ Maria Lopes dos Santos, ${ }^{4, *}$, Daniele Maria Alves Teixeira Sá ${ }^{5}$ e Antônia Lucivânia de Sousa \\ Monte $^{6}$
}

O objetivo deste trabalho foi avaliar a qualidade microbiológica e físico-química de sorvetes comercializados a granel em Limoeiro do Norte, Ceará, Brasil. Amostras de sorvete, sabor chocolate, foram coletadas em cinco estabelecimentos que comercializam gelados comestíveis a granel tipo self-service. Foram determinados coliformes termotolerantes, Escherichia coli, estafilococos coagulase positiva e Salmonella sp., além dos parâmetros físicoquímicos e composição centesimal. Os resultados foram comparados com os obtidos na análise de sorvetes industrializados e com a legislação brasileira. Os aspectos higiênicos sanitários dos estabelecimentos que comercializam sorvetes a granel foram avaliados por meio de uma lista de verificação em boas práticas. Todas as amostras de sorvetes comercializados a granel (100\%) e 60\% das amostras de sorvetes industrializados analisadas apresentaram-se em desacordo com os padrões microbiológicos preconizados pela legislação apresentando níveis inaceitáveis de coliformes termotolerantes e Staphylococcus aureus, o que pode estar associado às condições higiênicas dos estabelecimentos uma vez que $60 \%$ das sorveterias avaliadas foram classificadas no grupo III (alto risco) de acordo com a lista de verificação em boas práticas. Além disso, parte dos sorvetes apresentaram teores inferiores de proteínas e gorduras lácteas, sendo, portanto, necessária uma maior fiscalização por parte dos órgãos competentes a fim de evitar danos ao consumidor.

Palavras-chave: Consumidor, controle de qualidade, gelados comestíveis, self-service, sorveteria.

\section{Microbiological and physico-chemical quality of chocolate flavored ice cream commercialized in the city of Limoeiro do Norte, Ceará, Brazil}

The objective of this work was to evaluate the microbiological and physico-chemical quality of ice cream commercialized in bulk in Limoeiro do Norte, Ceará, Brazil. Samples of chocolate flavored ice cream were collected from five establishments which commercialize self-serving type edible ice creams. Thermotolerant coliforms, Escherichia coli, Staphylococcus coagulase positive and Salmonella sp. were determined, in addition to the physico-chemical parameters and centesimal composition. The results were compared with those obtained in an analysis of industrialized ice creams and with Brazilian legislation. The hygienic sanitary aspects of establishments that market ice cream in bulk were assessed by means of a checklist of good practices. All the samples of ice

\footnotetext{
${ }^{1}$ Mestre em Tecnologia de Alimentos, Doutorando em Biotecnologia, Rede Nordeste de Biotecnologia, Universidade Estadual do Ceará, Campus do Itaperi. E-mail: samuelbarcelos05@gmail.com; ORCID: 0000-0002-1706-9114.

${ }^{2}$ Mestre em Tecnologia de Alimentos, Professora do curso Tecnologia em alimentos do Intituto Federal de Educação, Ciência e Tecnologia do Piauí, Campus Teresina Central, E-mail: silvaedilene16@hotmail.com.

3 Mestre em Tecnologia de Alimentos, Intituto Federal de Educação, Ciência e Tecnologia do Ceará, Campus Limoeiro do Norte, E-mail: elisabethmariano@hotmail.com; ORCID: 0000-0001-5250-4110.

${ }_{4}^{4}$ Doutora em Engenharia Química, Professora do Curso de Mestrado em Tecnologia de Alimentos, Intituto Federal de Educação, Ciência e Tecnologia do Ceará, Campus Limoeiro do Norte. *Endereço para correspondência: Rua Estevão Remígio, 1145, Centro, Limoeiro do Norte - CE, Brasil. CEP: 62930-000, Telefone: +55 (88) 3447-6421. E-mail: anisulivan@gmail.com; ORCID: 0000-0001-9342-3931.

${ }_{5}^{5}$ Doutora em Bioquímica, Professora do Curso de Mestrado em Tecnologia de Alimentos, Intituto Federal de Educação, Ciência e Tecnologia do Ceará, Campus Limoeiro do Norte. E-mail: danielemaria@ifce.edu.br; ORCID: 0000-0001-5477-7526.

${ }^{6}$ Doutora em Zootecnia/Produção e Melhoramento Animal, Professora do Curso de Mestrado em Tecnologia de Alimentos, Intituto Federal de Educação, Ciência e Tecnologia do Ceará, Campus Limoeiro do Norte. E-mail: lucivania@ifce.edu.br; ORCID: 0000-0003-2504-5136.
} 
cream commercially available in bulk $(100 \%)$ and $60 \%$ of commercially processed ice cream samples were in disagreement with the microbiological standards recommended by the legislation, presenting unacceptable levels of thermotolerant coliforms and Staphylococcus aureus. This may be associated with the conditions, as $60 \%$ of the ice cream shops evaluated were classified in group III (high risk) according to the checklist for good practices. In addition, part of the ice cream presented lower levels of proteins and milk fats, and therefore greater supervision by the competent organs is necessary in order to avoid making consumers sick.

Keywords: Consumer, quality control, ice cream, self-service, ice cream shop.

\section{INTRODUÇÃO}

O sorvete é um alimento consumido em todas as partes do mundo, mesmo em países de clima frio, por pessoas de todas as faixas etárias devido às características de parcialmente congelado, a sensação refrescante transmitida durante $\mathrm{O}$ consumo e a doçura. Diariamente surgem novos sabores e novas formas de preparação ${ }^{[1,2]}$. A Associação Brasileira das Indústrias e do Setor de Sorvetes ${ }^{[3]}$ no Brasil, afirma que no ano de 2017 o consumo Nacional de sorvete per capita foi de 5,44 litros ao ano, sendo que sua produção foi de 1129 milhões de litros no mesmo ano, uma produção bem expressiva, a qual é associada ao grande consumo e importância de sua qualidade.

A Agência Nacional de Vigilância Sanitária através da Portaria no 266, de 22 de setembro de 2005 define gelados comestíveis como produtos alimentícios obtidos a partir de uma emulsão de gorduras e proteínas, com ou sem adição de outros ingredientes e substâncias, ou ainda como uma mistura de água, açúcares e outros ingredientes desde que não descaracterizem o produto[4]. Produzido através de uma emulsão estabilizada e pasteurizada, denominada calda, o sorvete através do congelamento combinado a agitação (batimento) e a incorporação de ar, apresenta-se como uma substância cremosa, suave e agradável ao paladar das pessoas, sendo composto por produtos lácteos, gordura, água, açúcar, estabilizantes, emulsificantes, corante e aromatizantes ${ }^{[5]}$.

O controle da contaminação e proliferação dos micro-organismos patogênicos no sorvete é de essencial importância, uma vez que ele não sofre qualquer tipo de tratamento térmico após a sua fabricação, por isso, pode-se constituir um veículo capaz de transmitir micro-organismos causadores de toxinfecções. A microbiota patogênica dos sorvetes pode ser associada aos ingredientes utilizados na sua produção e, principalmente aqueles à base de leite e ovos são potencialmente perigosos à saúde, pois possuem nutrientes fundamentais para $O$ crescimento e mutiplicação da maioria dos microorganismos, incluindo os patogênicos[ ${ }^{[6]}$, mais também podem ser adquiridos durante a fabricação do produto, pela deficiência e/ou ausência das boas práticas de fabricação.

O atendimento dos padrões microbiológicos e químicos são de suma importância no controle de qualidade na fabricação de gelados comestíveis, pelo mesmo possuir uma estrutura extremamente sensível, que quando passa por aumento de temperatura pode acarretar o aumento da atividade de água, propiciando mudanças nas suas características desejaveis, como o desenvolvimento de cristais de gelo e o desenvolvimento e disseminação de microorganismos causadores de toxinfecções[7].

O sorvete é um meio ideal para o crescimento microbiano devido ao seu alto valor nutritivo, $\mathrm{pH}$ próximo ao neutro e longo período de armazenamento[8]. Depois que o sorvete é contaminado, a temperatura de congelamento não pode tornar o produto mais seguro[?], pois alguns micro-organismos patogênicos conseguem manterse viáveis em produtos mesmo sendo mantidos sob temperatura de congelamento, como o Staphylococcus aureus e a Salmonella sp. ${ }^{[10] .}$

O modelo de venda ao consumidor tipo selfservice ou autosserviço tem propiciado o aumento das chances de ocorrência de contaminação dos produtos alimentícios pelos consumidores, pois os clientes mantêm contato direto com os produtos no balcão de autosserviço ${ }^{[11-13]}$. Por isso, tanto no modelo de venda ao consumidor tipo self-service (autosserviço) e no modelo de venda indireta (indústrias), deverá ser prática comum o monitoramento dos chamados Pontos Críticos de 
Controle para não aumentar a chance da ocorrência de contaminação por ineficiência da cadeia produtiva. Para isso, os fabricantes devem considerar além dos ingredientes e tratamento térmico, a manipulação durante toda a cadeia da produção e comercialização de sorvetes.

Este estudo objetiva avaliar a qualidade microbiológica e físico-química de sorvetes comercializados a granel em Limoeiro do Norte, Ceará, Brasil.

\section{MATERIAL E MÉTODOS}

\section{Coleta de amostras}

Foram selecionadas para participar deste estudo as cinco principais sorveterias que comercializam gelados comestíveis a granel tipo selfservice localizadas no centro do município de Limoeiro do Norte, Ceará, Brasil, no período de 31 de março a 02 de abril de 2016. Para fins de comparação, também foram escolhidas, cinco marcas de sorvetes industrializados, adquiridas nos principais supermercados localizadas no centro do município de Limoeiro do Norte, no mesmo período.

O critério de escolha do sorvete sabor "chocolate" foi baseado em pesquisa da Associação Brasileira das Indústrias e do Setor de Sorvetes ${ }^{[14]}$ no Brasil, que reporta que os sabores de maior comercialização e consumo no Brasil são: Chocolate $(28,8 \%)$, baunilha $(10,3 \%)$ e morango $(9 \%)$.

Duas amostras de sorvete sabor chocolate foram coletadas (em embalagens apropriadas, previamente higienizadas com álcool a $70 \%$ ) por sorveteria, as quais foram codificadas como: Sorvete a Granel (SG) tipo self-service [A a E - Formando o grupo constituído por cinco estabelecimentos]. Amostras de sorvetes industrializados também foram coletadas em duplicata (as amostras coletadas apresentaram embalagens íntegras e mesmo lote de fabricação) e analisadas para fim de comparação, as quais foram codificadas como: Sorvetes Industrializados (SI) [F a J - Formando o grupo constituído por cinco marcas], perfazendo um total de dez amostras de sorvetes, coletadas aleatoriamente, em duplicata.

\section{Caracterização das sorveterias a granel tipo self-service}

Para a análise do panorama higiênico sanitário (área de exposição dos sorvetes) do grupo de estabelecimentos que comercializam gelados comestíveis a granel tipo self-service $(n=5)$ foi elaborado uma Lista de Verificação em Boas Práticas (LVBP), com base nos preceitos do anexo da Resolução de Diretoria Colegiada $n^{\circ}$ 267/2003[15], que dispõe sobre o Regulamento Técnico de Boas Práticas de Fabricação para Estabelecimentos Industrializadores de Gelados Comestíveis e a Lista de Verificação das Boas Práticas de Fabricação para Estabelecimentos Industrializadores de Gelados Comestíveis.

A LVBP foi constituída pelos itens: Entrada da sorveteria [(está limpa?), (livre de objetos sem uso?)]; Piso (limpo e adequado?); Refrigeradores [(estão cobertos corretamente?), (limpos e sem acúmulo de gelo e/ou resíduos?) e (organizados?)]; Latas de lixo [(são suficientes?), (estão limpas?), (em bom estado de conservação?) e (forradas com saco de lixo?)]; Pias (existe pia exclusiva para lavagem de mãos?); Ventilação adequada?; Iluminação apropriada?; Limpeza das mesas, balcões e pias?; Funcionários [(os funcionários manipuladores de sorvete estão uniformizados?), (seus uniformes estão limpos e íntegros?), (estão de touca?), (estão com ou sem acessórios?), (com feridas abertas ou outras lesões que possam gerar contaminação?), (a higiene pessoal está de acordo com as normas: unhas, cabelos, pele, etc?), (espirram sobre os alimentos?), (tossem?), (fumam?) e (manipulam dinheiro? e/ou praticam outros atos que possam contaminar o alimento?)].

A LVBP foi devidamente preenchida fora do estabelecimento por pessoas habilitadas após a aquisição das amostras de sorvete, por meio de observação visual do estabelecimento comercializador de gelados comestíveis.

A verificação da adequação dos estabelecimentos quanto as Boas Práticas de Fabricação foram realizadas com base na Resolução RDC no 267, de 25 de setembro de 2003[15] a qual classifica os estabelecimentos em grupos de risco: Grupo I - Estabelecimento de baixo risco $[76 \%$ a $100 \%$ de conformidade]; Grupo II Estabelecimento de médio risco $[51 \%$ a $75 \%$ de conformidade] e Grupo III - Estabelecimento de 
alto risco $[0 \%$ a $50 \%$ de conformidade], de acordo com o panorama sanitário dos estabelecimentos industrializadores de gelados comestíveis.

\section{Qualidade Microbiológica}

A determinação e pesquisa de coliformes termotolerantes, Escherichia coli, estafilococos coagulase positiva e Salmonella sp. foram realizadas de acordo com a legislação brasileira, Resolução RDC no 12, de 2 de janeiro de 2001[16], que indica o padrão microbiológico para gelados comestíveis e produtos especiais gelados a base de leite e produtos lácteos (sorvetes e picolés com ou sem cobertura, sanduíche e bolo de sorvete) e similares.

A coleta das amostras e o preparo para as análises foram feitos de acordo com os procedimentos recomendado pelo Instituto Adolfo Lutz $^{[17]}$ e Brasil[16]. As amostras adquiridas foram acondicionadas em caixa térmica (Soprano, $28 \mathrm{~L}$, ref: 09018.0180.17) e imediatamente encaminhadas ao Laboratório de Microbiologia do Instituto Federal de Educação, Ciência e Tecnologia do Ceará (IFCE) Campus Limoeiro do Norte e armazenadas sob temperatura de congelamento ($20{ }^{\circ} \mathrm{C}$ ) até o início das análises. Antes do início das análises microbiológicas, os sorvetes foram descongelados a temperatura de refrigeração $\left(4{ }^{\circ} \mathrm{C}\right)$ por 60 minutos, para uma melhor homogeneização das amostras e o exterior das embalagens dos sorvetes a granel tipo self-service e industriais foram desinfetados com álcool a 70\%.

Para as análises microbiológicas, porções de cada amostra de sorvete foram recolhidas assepticamente $(25 \mathrm{~g})$ e diluídas em solução salina 0,85\% (p/v) (225 g) utilizando-se um homogeneizador Bag Mixer (Interscience, St. Nom, França) por 160 segundos. Diluições decimais subsequentes foram preparadas utilizando o mesmo diluente. Coliformes termotolerantes (coliformes a $45^{\circ} \mathrm{C}$ ), Escherichia coli e estafilococos coagulase positiva, foram determinados em duplicata por semeadura com inoculação de $1 \mathrm{~mL}$ de cada diluição em placas Petrifilm (3M Microbiology, St. Paul, MN, EUA) para contagens de coliformes (incubadas a $45{ }^{\circ} \mathrm{C} / 24 \mathrm{~h}$ ); de E. coli, (incubadas a $35-37^{\circ} \mathrm{C} / 24 \mathrm{~h}$ ) e de $S$. aureus (incubadas a $35-37$ ${ }^{\circ} \mathrm{C} / 24 \mathrm{~h}$ ), segundo métodos AOAC $991.14 \mathrm{e}$ AOAC 2003.08[18,19].
A presença de Salmonella sp. em amostras de sorvetes foi investigada seguindo metodologia convencional, preconizada pela American Public Health Association ${ }^{[20]}$. A análise foi realizada em duplicata.

\section{Composição centesimal dos sorvetes de chocolate}

As análises de composição centesimal realizada nos sorvetes de chocolate foram: Umidade $\left(\%\right.$, g.100 g $\left.{ }^{-1}\right)$; Proteínas $\left(\%\right.$, g.100 $\left.\mathrm{g}^{-1}\right)$ estimada com base no teor total de nitrogênio, determinado pelo método de Micro-Kjeldahl, usando fator de conversão de 6,38; Cinzas (\%, g.100 g-1), de acordo com os métodos descrito pelo IAL ${ }^{[17]}$ A determinação quantitativa de lipídios totais $(\%$, g.100 $\mathrm{g}^{-1}$ ), foi realizado segundo metodologia desenvolvida por Bligh e Dyer[21], com adaptações do IAL ${ }^{17]}$. Carboidrato total $\left(\%\right.$, g.100 g $\left.\mathrm{g}^{-1}\right)$, por diferença e Valor Calórico Total em kcal.100 g-1 calculado pela soma dos resultados das multiplicações dos valores encontrados de proteína, carboidratos e lipídios, pelos seus respectivos fatores de conversão (4, 4 e $9 \mathrm{kcal})^{[22]}$. Todas as análises foram realizadas em triplicata.

\section{Caracterização físico-química dos sorvetes de chocolate}

As análises físico-químicas realizadas nos sorvetes de chocolate foram: $\mathrm{pH}$ em potenciômetro de bancada (Lucadema, Luca-210); sólidos solúveis em refratômetro digital de bancada (Abbe Refratometer, Optronics-WYA-1S) com resultados expressos em ${ }^{\circ}$ Brix e acidez titulável por titulação com solução de $\mathrm{NaOH}(0,1 \mathrm{M})$ com resultados expressos em mg de ácido lático. ${ }^{-1}$ de acordo com os métodos do IAL[17]. Todas as análises foram realizadas em triplicata.

\section{Análise estatística}

Foram verificados os pressupostos de normalidade e homogeneidade das variáveis, respectivamente pelo teste de Shapiro-Wilk e Bartlett, todas as variáveis apresentaram distribuição normal e homogeneidade. Foi utilizado a Análise de Variância seguido da comparação entre os pares de médias pelo teste de Tukey $(p<0,05)$. O software estatístico utilizado para as análises foi o programa estatístico R, versão 3.5.0 (R Core Team, 2018)[23]. Os dados coletados por meio de questionário 
(LVBP) foram apresentados como média e porcentagem, por meio de estatística descritiva simples. Os resultados foram comparados com os resultados obtidos na análise de sorvetes industrializados e com a legislação brasileira vigente.

\section{RESULTADOS E DISCUSSÃO}

\section{Caracterização das sorveterias a granel tipo self-service}

Os resultados obtidos da aplicação da Lista de Verificação em Boas Práticas (LVBP) elaborada exclusivamente para esse estudo, são apresentados no Gráfico 1.

Gráfico 1. Resultados da lista de verificação em boas práticas dos estabelecimentos que comercializam gelados comestíveis a granel tipo selfservice na cidade de Limoeiro do Norte, Ceará, Brasil.

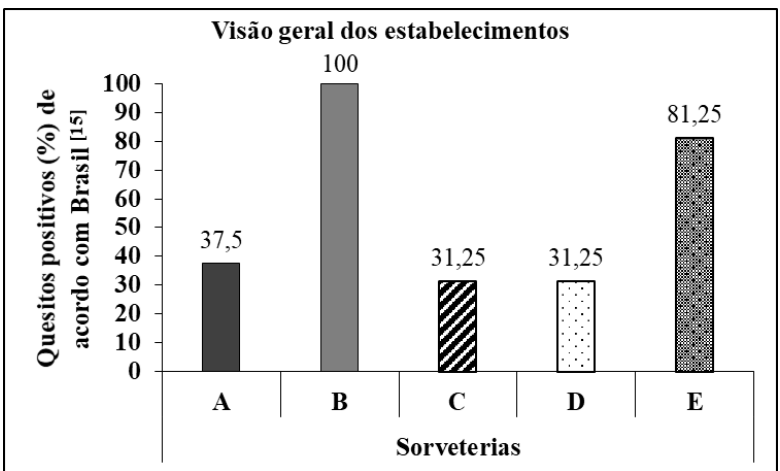

Fonte: Os Autores. Limoeiro do Norte, Ceará, Brasil, 31 de março a 02 de abril de 2016.

Como visualizado no Gráfico 1, apenas $40 \%(n=2)$ das sorveterias (B e E) foram classificadas no grupo I (Baixo risco). As demais sorveterias, $60 \%(n=3)$ foram classificadas no grupo III (alto risco), estando dessa forma, em desacordo com a legislação vigente ${ }^{[15]}$. A sorveteria B se destacou por apresentar $100 \%$ de adequação para os itens verificados pela LVBP.

Os itens da LVBP referente à higiene do armazenamento dos sorvetes e a salubridade física (saúde e bem-estar físico) dos manipuladores, apresentaram-se satisfatórias em 100\% $(n=5)$ das sorveterias estudadas, mostrando a preocupação dos estabelecimentos com o acondicionamento do seu produto, visto que no modelo de venda direta ao consumidor, ou self service, os freezers estão intimamente ligados com a apresentação do sorvete.
Entretanto, em apenas $60 \%(n=3)$ das sorveterias o armazenamento dos sorvetes era feito de maneira organizada. A salubridade física dos manipuladores durante a preparação e venda dos produtos deve atender o exigido pela legislação para alimentos seguros, pois os mesmos estão em contato com o produto a ser vendido, sendo de suma importância sua saúde física, tanto do ponto de vista microbiológico sanitário, como humano, também mostrando preocupação com a qualidade do produto exposto para venda. Quanto aos itens referentes a entrada da sorveteria está limpa, livre de objetos sem uso, pias exclusivas para a lavagem de mãos e utilização de acessórios, $60 \%(n=3)$ das sorveterias visitadas estavam de acordo com a legislação brasileira.

Os itens referentes à disponibilidade de lixeiras, ventilação, iluminação, limpeza das mesas, balcões e pias, padronização de um uniforme e limpeza do mesmo, apresentaram-se insatisfatórios, pois apenas $40 \%(n=2)$ das sorveterias estudadas estavam em conformidade com a legislação, concomitantemente $20 \%(n=1)$ não apresentava um uniforme padrão. $\mathrm{O}$ mesmo aconteceu para os itens referente a limpeza e adequação do piso, utilização de toucas pelos manipuladores e ao comportamento higiênico dos manipuladores, onde foi constatado que em $80 \%(n=4)$ das sorveterias apresentaram falta de limpeza e utilização de toucas para a manipulação e também comportamento higiênico incoerente para a preparação e venda dos sorvetes.

\section{Qualidade microbiológica}

Para averiguar a influência dos aspectos associados a deficiência e/ou ausência de algumas boas práticas de manipulação (funcionários), armazenamento e da qualidade higiênico-sanitário das instalações (área de exposição dos sorvetes) do grupo de estabelecimentos que comercializam gelados comestíveis a granel tipo self-service $(n=5)$, relatadas pela LVBP, foi realizado a determinação e pesquisa dos patógenos: Coliformes termotolerantes, Escherichia coli, estafilococos coagulase positiva e Salmonella sp., em duas amostras de sorvete de chocolate por sorveteria (Tabela 1).

Para Staphylococcus aureus a legislação vigente ${ }^{[16]}$ estabelece para gelados comestíveis à base de leite, um padrão de no máximo 5 x $10^{2} \mathrm{UFC} \cdot \mathrm{g}^{-1}$, 
equivalente a 2,698 Log UFC.g-1 ${ }^{-1}$. Todas as amostras de SG tipo self-service revelaram população superior ao permitido pela legislação, apresentando entre 3,38 a 4,49 Log UFC.g-1 (Tabela 1).

Tabela 1. Contagem (média $\pm \mathrm{DP})^{1}$ de micro-organismos indicadores de contaminação (Log UFC.g-1) obtidas para os Sovertes de chocolate a Granel (SG) tipo self-service e Industrializados (SI) comercializados na cidade de Limoeiro do Norte, Ceará, Brasil.

\begin{tabular}{ccccc}
\hline \multirow{2}{*}{ Sorvetes* } & \multicolumn{4}{c}{ Populações de micro-organimos (Log UFC.g-1) } \\
\cline { 2 - 5 } & $\begin{array}{c}\text { Staphylococcus } \\
\text { aureus }\end{array}$ & $\begin{array}{c}\text { Coliformes } \\
\text { termotolerantes }\end{array}$ & Escherichia coli & Salmonella sp. \\
\hline SG-A & $4,49 \pm 0,14$ & $2,65 \pm 0,00$ & $1,08 \pm 0,15$ & Ausência \\
SG-B & $4,04 \pm 0,04$ & $>3$ & $<1$ & Ausência \\
SG-C & $4,06 \pm 0,06$ & $>3$ & $1,66 \pm 0,45$ & Ausência \\
SG-D & $3,52 \pm 0,45$ & $2,99 \pm 0,04$ & $<1$ & Ausência \\
SG-E & $3,38 \pm 0,62$ & $3,06 \pm 0,04$ & $<1$ & Ausência \\
\hline SI-F & $2,54 \pm 0,09$ & $3,03 \pm 0,01$ & $<1$ & Ausência \\
SI-G & $<1$ & $2,49 \pm 0,05$ & $<1$ & Ausência \\
SI-H & $<1$ & $<1$ & $<1$ & Ausência \\
SI-I & $<1$ & $2,27 \pm 0,08$ & Ausência \\
SI-J & $<1$ & $<1$ & $<1$ & Ausência \\
\hline Limites & 2,698 & 1,698 & - & Ausência
\end{tabular}

(\#) Padrões microbiológicos segundo a RDC no 12, de 2 de janeiro de 2001[16]; (*) SG [A a E] = Sorvetes comercializados em sorveterias que vendem gelados comestíveis a granel tipo self-service; SI $[\mathrm{F}$ a J] = Sorvetes industrializados; $\left({ }^{1}\right)$ Média de quatro repetições \pm desvio padrão, referente a determinação em duas amostras $(n=$ 2); $(-)=$ sem limites estabelecidos.

Fonte: Os Autores. Limoeiro do Norte, Ceará, Brasil.

O mesmo nível de contaminação não foi observado para as amostras de SI. A presença de $S$. aureus foi verificada apenas na amostra $\mathrm{F}$ de SI $(20 \%)$, que apresentou contaminação próxima ao máximo preconizado pela legislação vigente ${ }^{[16]}$ para gelados comestíveis, de 2,54 Log UFC.g-1 ${ }^{-1}$ as demais amostras, equivalente a $80 \%$ não apresentaram contaminação $\left(<1 \mathrm{Log} \mathrm{UFC} \cdot \mathrm{g}^{-1}\right)$. A presença desse micro-organismo nos alimentos está fortemente relacionada a ausência ou deficiência das BPF's, por ser indicativo de contaminação a partir da pele, boca, fossas nasais, mãos e roupas dos manipuladores, bem como da limpeza e da sanitização inadequada dos materiais e equipamentos, que quando em contato com os alimentos podem agir como uma fonte de contaminação[?].

A maior contaminação dos SG, tipo selfservice pode está fortemente relacionada além da deficiência dessas práticas, a maneira de sua comercialização, por se tratar de uma venda direta ao consumidor, onde o sorvete fica exposto a condições sanitárias impróprias, como contato direto com o ar ambiente, falta de controle da qualidade da água utilizada para a limpeza, acondicionamento das colheres e contaminação por saliva e outras secreções oriundas dos consumidores e dos funcionários do estabelecimento. Portanto, os produtores de gelados (sorvete) não podem somente considerar o processo de pasteurização e congelamento satisfatório para a prevenção da contaminação e proliferação dos micro-organismos patogênicos ${ }^{[24,13]}$.

Apesar de ser um produto congelado, o sorvete também é sensível a contaminação por agentes microbiológicos, como qualquer outro alimento rico em nutrientes e com alta quantidade de água em sua constituição. A necessidade da baixa temperatura para a conservação do sorvete não pode ser confundida com sua inocuidade, por isso, é importante que o local de comercialização do produto também possa garantir a sua manutenção e qualidade. De acordo com Halpin-dohnalek, Marth ${ }^{[25]}$ o $S$. aureus é resistente a ciclos de 
congelamento e descongelamento e sobrevive durante longos períodos em alimentos armazenados a temperaturas inferiores $\mathrm{a}-20^{\circ} \mathrm{C}$.

No presente trabalho, a contaminação por $S$. aureus nos sorvetes sabor chocolate comercializados nas soveterias a granel tipo selfservice (B, C, D e E) e industrializado (F) (Tabela 1) foram semelhantes às reportadas por Rodrigues et al.[26] que em estudo das condições higiênicosanitárias de sorvetes sabor chocolate comercializados na cidade de Pombal, Paraíba-PB, adquiridos em cinco sorveterias da cidade, evidenciaram contaminação pelo patógeno entre 1,0 e 2,8 x $10^{3}$ (respectivamente equivalente a 3,0 e 3,4 Log UFC.g $\left.{ }^{-1}\right)$.

Estudo semelhante ao do presente trabalho foi realizado na Índia por Jadhav e Raut[27], com sorvetes de marca, sem marca e de self-made (feito pelo próprio vendedor), coletados em lojas populares de gelados comestíveis, vendedores ambulantes e sorveterias. Entre eles os que obtiveram maior ocorrência de contaminação por $S$. aureus foram os sorvetes vendidos por vendedores ambulantes na cidade de Kolhapur, Maharashtra, na Índia, que apresentaram contaminação de até 7 UFC. $\mathrm{g}^{-1}$, contaminação essa superior as encontradas para as amostras de sorvete que apresentaram contaminação por $S$. aureus do presente trabalho (Tabela 1).

Kokkinakis et al.[28] realizaram um estudo de Análise de Perigo e Pontos Críticos de Controle (APPCC) em uma indústria de processamento de gelados comestíveis em Siteia, Creta, na Grécia, onde avaliaram a produção de sorvete de chocolate e outros sabores. Os autores constataram que dentre as 15 amostras de sorvete de chocolate analisadas, 9 tiveram contaminação positiva para $S$. aureus antes da aplicação do APPCC e depois da aplicação do APPCC não foi detectada a presença do patógeno nas amostras, mostrando a necessidade da implementação de programas de qualidade e treinamento dos funcionários para a melhoria da qualidade dos produtos e serviços oferecidos pelos estabelecimentos. No Brasil, a implantação das BPF's e do sistema de APPCC para os fabricantes de gelados comestíveis é obrigatória e instituída pela Resolução - RDC no 267, de 25 de setembro de 2003[15], da Agência Nacional de Vigilância Sanitária (ANVISA), mas nem sempre é colocada em prática. De acordo com White et al.[29] deve-se oferecer treinamento aos manipuladores para aperfeiçoar tanto sua higiene pessoal quanto a higiene ambiental e dos alimentos.

Com relação aos resultados obtidos para coliformes termotolerantes ou coliformes a $45{ }^{\circ} \mathrm{C}$ (Tabela 1), 100\% das amostras de SG e 60\% das amostras de SI (F, G e I) apresentaram contaminação superior ao preconizado pela legislação vigente ${ }^{[16]}$. Apenas duas amostras de SI $(\mathrm{H}$ e J) não apresentaram contaminação $(<1 \quad$ Log UFC. $\left.\mathrm{g}^{-1}\right)$. Isso revela que grande parte dos estabelecimentos que comercializam sorvetes precisam se atentar mais as BPF's, para que doenças transmitidas por alimentos (DTA's) sejam evitadas.

Oliveira et al.[30] avalliaram coliformes a 45 ${ }^{\circ} \mathrm{C}$ em amostras de sorvetes comercializados nos principais supermercados de Maceió - Alagoas, das quatro amostras analisadas 50\% obteve valor $<3,0$ NMP. $\mathrm{mL}^{-1}$, estando dentro do limite estabelecido pela legislação brasileira vigente ${ }^{[16]}$, apresentando contaminação inferior a todas às amostras de SG $(\mathrm{A}, \mathrm{B}, \mathrm{C}, \mathrm{D}$ e E) e, às amostras de SI (F, G e I) estudadas pelo presente trabalho, mas assemelharam-se com as demais amostras estudadas pelo autor, que apresentaram valores entre $1.100 \mathrm{e}$ $>1.100$ NMP.mL ${ }^{-1}$, em desacordo com a legislação vigente, indicando condições higiênicas e sanitárias inadequadas. Souza et al.[13] também encontraram contaminação por coliformes termotolerantes em sorvetes sabor chocolate, comercializados em sorveterias self-service da cidade de Sinop, Mato Grosso, onde $40 \%$ das amostras apresentaram-se em desacordo com os padrões microbiológicos da legislação vigente ${ }^{[16]}$.

Os resultados obtidos para Escherichia coli no presente trabalho (Tabela 1) mostrou que dentre as cinco amostras de sorvete de chocolate comercializadas a granel, duas $(40 \%)$ (A e C) apresentaram presença de $E$. coli, sendo as três restantes livres de tal contaminação, já as cinco amostras de SI, apresentaram-se livres do patógeno. A legislação brasileira vigente[16] não estabelece valores padrões para contagem de E. coli, entretanto fica subentendido que os gelados comestíveis devem ser inócuos desse micro-organismo, em virtude da contagem de E. coli ser utilizada como o principal indicador de contaminação fecal, visto que tem seu habitat exclusivo no trato intestinal do homem e de animais. A sua presença em alimentos evidencia condições sanitárias inadequadas durante 
o processamento, produção ou armazenamento, e altas contagens podem significar contaminação pósprodução, limpezas e sanitizações deficientes, assim como tratamentos térmicos ineficientes ${ }^{[31]}$.

Jadhav e Raut ${ }^{27}$ obtiveram o mesmo resultado do presente trabalho, onde das amostras de sorvete avaliadas, $40 \%$ apresentaram-se contaminadas por E. coli. No entanto, em trabalho realizado por Souza et al.[13], com sorvetes sabor chocolate adquiridos em sorveterias self-service da cidade de Sinop, Mato Grosso, os autores detectaram que todas as amostras analisadas estavam contaminadas por E. coli, demonstrando ainda mais a necessidade do cuidado com esse tipo de autosserviço (self-service).

Na Tabela 1, os resultados obtidos para Salmonella sp. foram satisfatórios, os quais foram detectados ausência em 100\% das amostras analisadas (SG tipo self-service e SI), assim estando de acordo com a legislação vigente ${ }^{[16]}$, apresentado ausência desta bactéria em $25 \mathrm{~g}$ de amostra.

Resultados diferentes ao do presente trabalho foram obtidos por vários autores, entre eles, por Oliveira et al. ${ }^{30]}$ em amostras de sorvetes comercializados nos principais supermercados da cidade de Maceió, por Souza et al.[13] em sorvetes sabor chocolate adquiridos em sorveterias self-service da cidade de Sinop, Mato Grosso e, em estudo realizado na Índia por Jadhav e Raut ${ }^{[27]}$ em sorvetes de marca, sem marca e de self-made (feito pelo próprio vendedor), onde os autores evidenciaram crescimento positivo de Salmonella sp., respectivamente em $100 \%, 90 \%$ e $33 \%$ das amostras analisadas.

Pazianotti et al.[32] avaliaram 21 amostras de sorvetes artesanais e industriais, comercializados na região de Arapongas, Paraná e verificaram que todas as amostras apresentaram ausência de Salmonella sp., entretanto, $52,38 \%$ das amostras apresentaram contaminação superior ao limite tolerável estabelecido pela legislação vigente ${ }^{[16]}$, para coliformes termotolerantes e 9,52\% das amostras para S. aureus. Os autores atribuíram essa contaminação a qualidade do leite utilizado, a deficiência da pasteurização, ao elevado conteúdo de umidade dos sorvetes, ao $\mathrm{pH}$ próximo da neutralidade e sua composição nutricional.
A partir dos dados apresentados pode-se inferir que apesar do resultado satisfatório para Salmonella sp., detectou-se níveis inaceitáveis de um ou mais micro-organismos nas amostras de sorvete de chocolate do presente trabalho (Staphylococcus aureus, Escherichbia coli e Coliformes termotolerantes) em 100\% das amostras de SG tipo self-service e em $60 \%$ das amostras de SI, tornando tais amostras impróprias para consumo. Esses resultados reforçam a existência de condições higiênicas inadequadas na comercialização dos SG tipo selfservice em estudo, verificadas pela aplicação da LVBP, revelando a necessidade da aplicação das BPF's. A RDC no 267/2003[15], dispõe sobre o Regulamento Técnico de BPF's para Estabelecimentos Industrializadores de Gelados Comestíveis, onde as indústrias produtoras de sorvete podem se basear para a melhoria da qualidade microbiológica de seus produtos.

Traçando um comparativo, é possível verificar claramente a prevalência de contaminação por E. coli quando o estabelecimento foi classificado no Grupo III [0\% a 50\% de conformidade], após a aplicação da LVBP. No entanto, não houve uma relação direta do perfil das boas práticas de higiene das sorveterias e todos os microrganismos analisados como é observado relacionando o (Gráfico 1) com os resultados das análises microbiológicas dos SG tipo self-service (Tabela 1). Observa-se que a sorveteria B se destacou por apresentar $100 \%$ de adequação para todos os itens da LVBP e a sorveteria E com 81,25\% de adequação aos itens da LVBP, no entanto, os sorvetes de chocolate coletados nessas sorveterias apresentaram populações superiores ao permitido pela legislação brasileira vigente ${ }^{[16]}$, para os patógenos $S$. aureus e coliformes termotolerantes (coliformes a $45 \quad{ }^{\circ} \mathrm{C}$ ), assemelhando-se as populações encontradas para esses mesmos microrganismos em amostras de sorvete das sorveterias (A, C e D) que apresentaram baixa adequação $(\leq 37,5 \%)$ aos itens da LVBP.

Entretanto, a capacidade da LVBP de conseguir ser preditiva da qualidade microbiológica dos sorvetes, pode ter sido afetada: pela qualidade "inicial" dos sorvetes que são adquiridos pelas sorveterias, para serem revendidos pelo modelo de venda tipo self-service [esse argumento se sustenta com os próprios resultados do presente trabalho, onde as amostras de SI apresentaram contaminação por um ou mais patógenos ( $S$. aureus e coliformes 
termotolerantes), como mostra a Tabela 1] e também, pelo modelo de venda ao consumidor tipo self-service, por se tratar de uma venda direta ao consumidor, onde os clientes mantêm contato direto com os produtos no balcão de autosserviço, aumenta as chances de ocorrência de contaminação dos produtos alimentícios pelos consumidores [11-13]. Portanto, apenas as boas práticas de higiene (manipulação pelos funcionários e armazenamento adequado) e qualidade higiênicas sanitário desses estabelecimentos (tipo self-service), não conseguem garantir a qualidade microbiológica de um produto.

\section{Composição centesimal dos sorvetes de chocolate}

De maneira geral, observa-se que existiu diferença para todos os constituintes da composição centesimal entre o grupo de Sorvetes de chocolate a Granel (SG) tipo self-service e o grupo de Sorvetes de chocolate Industrializados (SI) (Tabela 2). No entanto, essa diferença pode ser justificada por se tratarem de fabricantes com diferentes formulações de sorvetes e, principalmente pela maneira de comercialização dos produtos, onde os SG tipo selfservice estão sujeitos a mudanças quantitativas em sua composição, pela constante abertura dos freezers do balcão self-service, estando eles sujeitos a perdas ou ganhos de umidade a depender da temperatura ambiente e da umidade relativa do ar, enquanto os SI são acondicionados fracionados em embalagens plásticas apropriadas, de diferentes volumes e abertas apenas no momento do consumo.

Tabela 2. Composição centesimal (média $\pm \mathrm{DP})^{1}$ dos Sovertes de chocolate a Granel (SG) tipo self-service e Industrializados (SI) comercializados na cidade de Limoeiro do Norte, Ceará, Brasil.

\begin{tabular}{ccccccc}
\hline Sovertes* & Umidade & Proteina & Cinzas & Lípidio & $\begin{array}{c}\text { Carboidrato } \\
\text { Total }\end{array}$ & $\begin{array}{c}\text { Valor calórico } \\
\text { Total }^{2}\end{array}$ \\
\hline SG-A & $62,81 \pm 0,53^{\mathrm{b}}$ & $1,80 \pm 0,00^{\mathrm{cd}}$ & $0,55 \pm 0,10^{\mathrm{f}}$ & $1,07 \pm 0,01^{\mathrm{f}}$ & $33,77 \pm 0,46^{\mathrm{bc}}$ & $150,94 \pm 0,53 \mathrm{~g}$ \\
SG-B & $60,74 \pm 0,15^{\mathrm{c}}$ & $1,70 \pm 0,17^{\mathrm{cd}}$ & $0,60 \pm 0,01^{\mathrm{ef}}$ & $1,41 \pm 0,02^{\mathrm{f}}$ & $35,55 \pm 0,07^{\mathrm{ab}}$ & $161,67 \pm 0,58^{\mathrm{e}}$ \\
SG-C & $63,57 \pm 0,50^{\mathrm{b}}$ & $4,20 \pm 0,00^{\mathrm{a}}$ & $0,71 \pm 0,04^{\mathrm{def}}$ & $1,82 \pm 0,05^{\mathrm{ef}}$ & $29,70 \pm 0,49^{\mathrm{d}}$ & $153,33 \pm 0,94^{\mathrm{fg}}$ \\
SG-D & $60,68 \pm 0,20^{\mathrm{c}}$ & $3,10 \pm 0,17^{\mathrm{abc}}$ & $0,88 \pm 0,05^{\mathrm{bcd}}$ & $2,96 \pm 0,28^{\mathrm{cd}}$ & $32,38 \pm 0,42^{\mathrm{c}}$ & $169,21 \pm 0,48^{\mathrm{d}}$ \\
SG-E & $67,20 \pm 0,23^{\mathrm{a}}$ & $3,59 \pm 0,42^{\mathrm{ab}}$ & $0,81 \pm 0,03^{\mathrm{cd}}$ & $2,27 \pm 0,06^{\mathrm{de}}$ & $26,14 \pm 0,76^{\mathrm{e}}$ & $139,07 \pm 0,82^{\mathrm{h}}$ \\
\hline SI-F & $63,10 \pm 0,49^{\mathrm{b}}$ & $1,40 \pm 0,35^{\mathrm{d}}$ & $0,75 \pm 0,05^{\mathrm{cde}}$ & $2,37 \pm 0,20^{\mathrm{de}}$ & $32,38 \pm 0,81^{\mathrm{c}}$ & $157,86 \pm 0,11^{\mathrm{ef}}$ \\
SI-G & $56,32 \pm 1,21^{\mathrm{de}}$ & $2,20 \pm 1,39^{\mathrm{bcd}}$ & $1,06 \pm 0,08^{\mathrm{a}}$ & $4,99 \pm 0,23^{\mathrm{a}}$ & $35,43 \pm 0,47 \mathrm{ab}$ & $193,18 \pm 1,71^{\mathrm{b}}$ \\
SI-H & $57,71 \pm 0,41^{\mathrm{d}}$ & $3,00 \pm 0,00^{\mathrm{abc}}$ & $0,88 \pm 0,03^{\mathrm{bc}}$ & $3,88 \pm 0,39^{\mathrm{b}}$ & $34,48 \pm 0,14^{\mathrm{bc}}$ & $184,85 \pm 4,10^{\mathrm{c}}$ \\
SI-I & $53,93 \pm 1,27^{\mathrm{f}}$ & $3,40 \pm 0,17^{\mathrm{ab}}$ & $0,89 \pm 0,05^{\mathrm{bc}}$ & $4,26 \pm 0,45^{\mathrm{ab}}$ & $37,39 \pm 1,64^{\mathrm{a}}$ & $202,23 \pm 1,89^{\mathrm{a}}$ \\
SI-J & $55,74 \pm 0,22^{\mathrm{ef}}$ & $4,50 \pm 0,42^{\mathrm{a}}$ & $1,03 \pm 0,08^{\mathrm{ab}}$ & $3,76 \pm 0,58^{\mathrm{bc}}$ & $34,90 \pm 0,54^{\mathrm{b}}$ & $191,45 \pm 1,32^{\mathrm{b}}$ \\
\hline
\end{tabular}

$\left(^{*}\right)$ SG $[\mathrm{A}$ a $\mathrm{E}]=$ Sorvetes comercializados em sorveterias que vendem gelados comestíveis a granel tipo selfservice; SI [F a J] = Sorvetes industrializados; (1) Média de três repetições \pm desvio padrão; Resultados expressos em base úmida $\left.\left(\%=\mathrm{g} .100 \mathrm{~g}^{-1}\right) ;{ }^{2}\right)$ Resultados expressos em kcal.100 $\mathrm{g}^{-1}$.

a, b, c, d, e, f, g Letras minúsculas sobrescritas distintas na mesma coluna indicam diferença significativa $(p<0,05)$ entre os sorvetes de chocolate pelo teste de Tukey.

Fonte: Os Autores. Limoeiro do Norte, Ceará, Brasil.

Em geral, também se observa que a composição centesimal entre as amostras do grupo de SG foram semelhantes, no entanto, ainda existiu amostras que diferiram estatisticamente $(p<0,05)$ das demais amostras do grupo, para todos os constituintes centesimais. $\mathrm{O}$ mesmo comportamento pode ser atribuído as amostras do grupo de SI. Entretanto esse comportamento já era esperado por si tratarem de amostras de sorvete de diferentes fabricantes.

Em relação a umidade, a amostra de SI-F foi a única que apresentou diferença estatística $(\phi<$ $0,05)$ entre todas as demais amostras do grupo de SI e, a única que apresentou semelhança estatística $(p>$ $0,05)$ com amostras do grupo de SG, apresentando um maior conteúdo de umidade. Isso pode ter 
tornado-a mais susceptível aos micro-organismos como o $S$. aureus, assim como os SG, visto que o SIF foi a única amostra de SI que apresentou crescimento para esse micro-organismo (Tabela 1).

Os sorvetes analisados (SG e SI) continham em sua composição valores médios de sólidos totais (100 - teor de umidade) de no mínimo 32,80\% (umidade $=67,20$, amostras de SG-E) e no máximo de 46,07\% (umidade $=53,93$, amostras de SI-I), estando de acordo com a legislação brasileira ${ }^{[33,4]}$, as quais estabelecem um valor mínimo de $28 \%$ para este parâmetro.

Quanto aos teores de proteínas (Tabela 2) existiu semelhança significativa $(p>0,05)$ entre as amostras de SG e SI, entre elas: (A, B, F e G), (G, E, D, H e I), (D, G, H, A, B), (F, G, A e B) e (D, E, $\mathrm{H}, \mathrm{I}$, J e C). Para o teor de proteínas em sorvetes, as legislações ${ }^{[33,4]}$ preconizam um teor mínimo de $2,5 \%$ de proteínas do leite, para sorvetes a base de leite. Os sorvetes aqui estudados, SG (A e B) e SI (G e $\mathrm{F})$, apresentaram $40 \%$ das amostras em desacordo com a legislação brasileira, exibindo teores de proteínas inferiores ao preconizado.

Para o teor de lipídios (Tabela 2), amostras de SG apresentaram semelhança significativa $(p>$ $0,05)$ com amostras de SI, entre elas: (D, E e F), (J e D) e (C, E e F). O constituinte lipídio também apresentou amostras de SG (A, B, C e E) e de SI (F) com teores de lipídios inferiores ao preconizado pelas legislações ${ }^{[33,4]}$, que preconizam que os sorvetes devem apresentar em sua composição um mínimo de 2,5\% de gordura láctea, apresentando $80 \%$ de inconformidade para os SG e $20 \%$ para os SI.

O teor de carboidratos totais dos sorvetes de chocolate estudados pelo presente trabalho (Tabela 2) apresentaram valores entre $26,14 \%$ a $37,39 \%$. Em geral, os SG apresentaram um menor teor de carboidratos totais em comparação com os SI, entretanto, ainda existiu semelhança significativa $(\not>0,05)$ entres as amostras de SG e SI: (A, B, G, $\mathrm{H}$ e J), (A, D, F e H) e (B, G e I).

De maneira geral, os SI $[80 \%$ (amostras G, $\mathrm{H}$, I e J)] apresentaram valor calórico total (Tabela 2) estatisticamente $(p<0,05)$ superior a todas as amostras de SG. Ambos os grupos de sorvetes de chocolate (SG e SI) estudados apresentaram aporte calórico com valores entre 69,53 a 101,11 kcal em
50 g do produto, porção recomendada pela Resolução RDC $\mathrm{n}^{\circ} 359$, de 23 de dezembro de 2003[34] para sorvetes.

Suzuki[35] encontrou em sorvetes sabor chocolate industrializados e comercializados na região de Maringá, Paraná-PR um percentual médio de 36,04\% para sólidos totais (umidade média = $63,96 \%$ ), 3,08\% para proteínas, 7,46\% para lipídios, $24,80 \%$ para carboidratos, $0,70 \%$ para cinzas e 178,66 para valor calórico total. Os valores obtidos pelo autor atendem os padrões mínimos exigidos para sólidos totais, proteínas e lipídios, preconizado por ambas as legislações brasileiras ${ }^{[3,4]}$.

Percentuais de sólidos totais, proteínas e lipídios em conformidade com ambas as legislações ${ }^{[33,4]}$ também foram obtidos em sorvetes estudados por Pazianotti et al. ${ }^{32]}$ em amostras de sorvetes artesanais e industriais comercializados na região de Arapongas, Paraná-PR, por Passos et al.[36] em estudo da incorporação de galactomanana de Caesalpinia pulcherrima em sorvetes sabor goiaba e, por Ramos[37] em estudo dos aspectos físicoquímicos, sensoriais e reológicos de sorvete gourmet elaborado com e sem redução do teor de lactose. Entretanto, Félix et al.[38] encontraram teor de lipídio de 1,88\% em sorvete sabor morango industrializado, comercializado na região de Salgueiro, Pernambuco-PE, teor esse inferior ao preconizado por ambas as legislações brasileiras $[33,4]$ e, similar ao teor de lipídios apresentados pelas amostras de SG (A, B, C e E) e SI (F) do presente trabalho, que também apresentaram teor de lipídios inferiores ao mínimo estabelecido.

Pazianotti et al.[32], avaliando amostras de sorvetes artesanais e industriais comercializados na região de Arapongas, Paraná-PR, observaram em média que o grupo de sorvete artesanal diferiu significativamente $(p<0,05)$ do grupo de sorvete industrial, tendo apenas o constituinte sólidos totais apresentado semelhança estatística $(\phi>0,05)$. Resultado semelhante pode ser observado no presente trabalho, onde de maneira geral o grupo de SG e o grupo de SI diferiram quanto a sua composição centesimal.

\section{Caracterização físico-química dos sorvetes de chocolate}

A Tabela 3 apresenta os valores de $\mathrm{pH}$, acidez titulável e sólidos solúveis dos Sorvetes de 
chocolate a Granel (SG) tipo self-service e dos Sorvetes de chocolate Industrializados (SI). No que diz respeito aos parâmetros físico-químicos, $\mathrm{o} \mathrm{pH}$ foi o único parâmetro que se observou diferença significativa $(\phi<0,05)$ entre o grupo de SG e o grupo de SI (Tabela 3). O grupo de SG apresentou valores de $\mathrm{pH}$ mais baixos, enquanto o grupo de SI valores de $\mathrm{pH}$ mais próximos a neutralidade. Contudo, foi observado semelhança significativa $(p$ $>0,05)$ entre as amostras do mesmo grupo, SI $(G, I$ e J) e, SG (A, B e D), (A, C e E) e (A, B e C).

Tabela 3. Análises físico-químicas (média $\pm \mathrm{DP})^{1}$ dos Sovertes de chocolate a Granel (SG) tipo self-service e industrializados (SI) comercializados na cidade de Limoeiro do Norte, Ceará, Brasil.

\begin{tabular}{cccc}
\hline Sovertes* & $\mathbf{p H}$ & $\begin{array}{c}\text { Acidez titulável } \\
\text { (mg de ác.lático.g }\end{array}$ & $\begin{array}{c}\text { Sólidos } \\
\text { solúveis }\end{array}$ \\
\hline SG-Brix)
\end{tabular}

$\left.{ }^{*}\right)$ SG $[\mathrm{A}$ a $\mathrm{E}]$ = Sorvetes comercializados em sorveterias que vendem gelados comestíveis a granel tipo selfservice; SI [F a J] = Sorvetes industrializados; (1) Média de três repetições \pm desvio padrão.

a, b, c, d, e, f Letras minúsculas sobrescritas distintas na mesma coluna indicam diferença significativa $(\phi<0,05)$ entre os sorvetes de chocolate pelo teste de Tukey.

Fonte: Os Autores. Limoeiro do Norte, Ceará, Brasil.

De modo geral, o mesmo comportamento observado para o parâmetro $\mathrm{pH}$, pode ser observado para os valores de acidez titulável ( $\mathrm{mg}$ de ác.lático. $\mathrm{g}^{-1}$ ), de maneira inversamente proporcional, onde as amostras de SG apresentaram valores de acidez titulável superiores as amostras de SI, apesar que, foi observado semelhança significativa $(p>$ $0,05)$ entre as amostras de SG e SI, entre elas: $(B, C$, E, G e I) e (A, D e J) para esse parâmetro.

Foi possível perceber (Tabela 3) que apesar de ter havido diferença significativa $(p<0,05)$ entre as amostras do grupo de SG e SI para os parâmetros físico-químicos $\mathrm{pH}$ e acidez titulável, os mesmos não apresentaram relação com o nível de contaminação das amostras. Embora, os sorvetes de chocolate aqui estudados possam ser classificados por meio do $\mathrm{pH}$, como alimentos de baixa acidez ( $\mathrm{pH} \geq 4,50)$, tornando-os sujeitos a multiplicação microbiana por micro-organismos patógenos e deteriorantes ${ }^{[39]}$. Isso revela mais uma vez a importância das BPF's, que estiveram mais presentes nas amostras do grupo de SI (Tabela 1).

Valores de $\mathrm{pH}$ e acidez titulável próximos aos sorvetes de chocolate (SG e SI) do presente trabalho (Tabela 3) foram obtidos por Ramos ${ }^{[37]} \mathrm{em}$ sorvetes gourmet elaborados com e sem redução do teor de lactose, que obtiveram respectivamente valores de $\mathrm{pH}$ de 7,07 e 7,00 e, acidez de 0,20\% de ácido lático. Outros autores como Pazianotti et al. [32] e Félix et al.[38] também encontraram valores de $\mathrm{pH}$ semelhantes aos sorvetes de chocolate (SG e SI) do presente trabalho, respectivamente em amostras de sorvetes artesanais e industriais comercializados na região de Arapongas, Paraná-PR (pH de 6,45 e 6,38, respectivamente) e em amostras de sorvete sabor morango industrializados, comercializados na região de Salgueiro, Pernambuco-PE ( $\mathrm{pH}$ de 6,80 e 6,84), contudo, apresentaram valores antagônicos para acidez titulável, com valores de acidez mais elevada que as amostras de sorvetes de chocolate do presente trabalho. 
Os valores de sólidos solúveis dos sorvetes de chocolate (SG e SI) são apresentados na Tabela 3. As amostras de SI (G, H, I e J) se destacaram por apresentar os maiores valores de sólidos solúveis $(p$ $<0,05)$, apresentando assim, mais açúcar em suas formulações, o mesmo comportamento foi observado para o constituinte centesimal carboidrato total, onde as amostras de SI também apresentaram maior teor, como mostra a Tabela 2 . Contudo, também existiu semelhança significativa ( $p$ $>0,05)$ para os sólidos solúveis, entre as amostras de SG e SI (A, B e F). A maior concentração de sólidos no sorvete é desejável, pois os sólidos vão propiciar uma melhor textura e cremosidade ao sorvete elaborado.

A concentração de sólidos solúveis dos sorvetes de chocolate (SG e SI) analisados pelo presente trabalho (Tabela 3) foram superiores as amostras de sorvetes sabor morango industrializadas, estudadas por Félix et al.[38], adquiridas no comercio da região de Salgueiro, Pernambuco, que obtiveram valores para sólidos solúveis de 28,00 e $25,67^{\circ}$ Brix.

\section{CONCLUSÃO}

Através da aplicação da Lista de Verificação em Boas Práticas foi possível concluir que os serviços e instalações das sorveterias estudadas da cidade de Limoeiro do Norte-CE necessitam de melhorias para a adequação das três sorveterias que foram classificados no grupo III (alto risco), que constitui 60\% das sorveterias avaliadas.

Conclui-se que das dez amostras de sorvetes sabor chocolate analisadas (sorvetes a granel tipo selfservice e industrializadas), as a granel tipo self-service estão em desacordo com os padrões microbiológicos preconizados pela legislação vigente em $100 \%$ das amostras, apresentando níveis inaceitáveis de um ou mais micro-organismo, o que é indicativo de falta de higiene. Já as amostras industrializadas apenas 40\% apresentaram-se aceitáveis para a comercialização. A alta contaminação dos sorvetes a granel tipo self-service podem está fortemente associada as más condições dos estabelecimentos reveladas pela aplicação da Lista de Verificação em Boas Práticas.

O controle microbiológico do sorvete é de fundamental importância uma vez que ele não sofre qualquer processo de cocção ou esterilização após o preparo final, com isso, pode-se constituir-se em veículo de disseminação de micro-organismos causadores de toxinfecções. Em função desses resultados, sugere-se que estas sorveterias e indústrias adotem as Boas Práticas de Fabricação e o Sistema de Análise de Perigos e Pontos Críticos de Controle, para assim melhorar a qualidade de seus produtos.

Ademais, das dez amostras de sorvetes de chocolate analisadas, $40 \%$ das amostras de sorvetes a granel tipo self-service e industrializadas apresentaram teores inferiores de proteínas e, $80 \%$ e $20 \%$ de gorduras lácteas, respectivamente, estando assim em desacordo com a legislação vigente.

\section{AGRADECIMENTOS}

Os autores agradecem a FUNCAP pela bolsa de estudos do 1ㅇ autor (Mestrado/IFCE), bem como a CAPES por seu suporte financeiro à pesquisa, além das bolsas de estudos do 2o, 3o (Mestrado/IFCE) e 4o (Pós-doutorado PNPD, CAPES/IFCE) autores.

\section{REFERÊNCIAS}

[1] Maia MCA, Galvão APGLK, Della-Modesta RC, Pereira-Júnior N. Avaliação sensorial de sorvetes à base de xilitol. Ciênc. Tecnol. Aliment. 2008;28(1):146-151.

[2] Bahram-Parvar M. A review of modern instrumental techniques for measurements of ice cream characteristics. Food chem. 2015;188:625-631.

[3] Associação Brasileira das Indústrias e do Setor de Sorvetes - ABIS. Produção e consumo de Sorvetes no Brasil. São Paulo, 2018. Retirado de: http://www.abis.com.br/estatistica_producaoeconsumo desorvetesnobrasil.html. [Acessado em: 02, Jan., 2019].

[4] Brasil. Ministério da Saúde. Regulamento técnico para gelados comestíveis e preparados para gelados comestíveis (Resolução n⿳0 266, de 22 de setembro de 2005). Diário Oficial [da] República Federativa do Brasil, Brasília, DF, 23 de setembro de 2005. Retirado de: https://www.saude.ri.gov.br/comum/code/MostrarArq uivo.php? $\mathrm{C}=\mathrm{MjIxMw} \% 2 \mathrm{C} \% 2 \mathrm{C}$. [Acessado em: 03, Jan., 2019].

[5] Souza JCB, Costa MR, Rensis CMVB, Sivieri K. Sorvete: Composição, processamento e viabilidade de adição de probiótico. Alim. Nutr. 2010;21(1):155-165.

[6] Falcão DP, Filho GS, Nishida NK, Borges SR. Exame microbiológico de sorvetes não pasteurizados. Ver. Saúde Públ. 1983;17(1):02-08. 
[7] Magalhães PJ, Broietti FCD. Gestão de Qualidade na Elaboração de Sorvetes. UNOPAR Cient. Exatas Tecnol. 2010;9(1):53-60.

[8] Bell C, Kyriakides A. Listeria: Apractical approach to the organism and its control in foods. Blackie Academic \& Porfessional: London. 150 p., 1998.

[9] Ambily R, Beena AK. Bacteriological quality of icecream marketed in Thrissur town, Kerala, India. Vet. World. 2012;5(12):738-741.

[10] Diogo GT, Aguiar GM, Tolentino MC, Buffara D, Pileggi M. Avaliação microbiológica de sorvetes comercializados na cidade de Ponta Grossa - PR e da água usada na limpeza das colheres utilizadas para servilos. Publ. UEPG Ci. Biol. Saúde. 2002;8(1):23-32.

[11] Alves MG, Ueno M. Restaurantes self-service: segurança e qualidade sanitária dos alimentos servidos. Rev. Nutr. 2010;23(4):573-580.

[12] Vedovato GM, Bastos DHM, Mancuso AMC, Behrens JH. A scale to evaluate customer atitudes towards food risks in restaurants. Vigil. sanit. debate. 2014;2(4):53-61.

[13] Souza JM, Santos ECG, Brito NJN, Silva GA. Análise microbiológica dos sorvetes self-service sabor chocolate da cidade de Sinop-MT. Demetra. 2015;10(4):857-866.

[14] Associação Brasileira das Indústrias e do Setor de Sorvetes - ABIS. Diario Econômico. São Paulo (31 de agosto de 2010). 2010. Retirado de: http://www.abis.com.br/noticias_2010_5.html.

[Acessado em: 02, Jan., 2019].

[15] Brasil. Ministerio da Saúde. Agência nacional de vigilância sanitária (ANVISA). Resolução - RDC no 267, de 25 de setembro de 2003. Dispõe sobre o Regulamento Técnico de Boas Práticas de Fabricação para Estabelecimentos Industrializadores de Gelados Comestíveis e a Lista de Verificação das Boas Práticas de Fabricação para Estabelecimentos Industrializadores de Gelados Comestíveis. Diário Oficial [da] República Federativa do Brasil, Brasília, DF, 26 de setembro de 2003. Retirado de: http://adcon.rn.gov.br/ACERVO/Suvisa/doc/DOC00 0000000022681.PDF. [Acessado em: 02, Jan., 2019].

[16] Brasil. Ministério da Saúde. Agência nacional de vigilância sanitária (ANVISA). Regulamento técnico sobre padrões microbiológicos para alimentos (Resolução RDC n⿳0 12, de 2 de janeiro de 2001). Diário Oficial [da] República Federativa do Brasil, Brasília, DF, 10 janeiro de 2001. Seção 1. Retirado de: http://portal.anvisa.gov.br/documents/33880/2568070/
RDC_12_2001.pdf/15ffddf6-3767-4527-bfac740a0400829b. [Acessado em: 03, Jan., 2019].

[17] Brasil. Instituto Adolfo Lutz - IAL. Normas Analíticas do Instituto Adolfo Lutz: Métodos físicoquímicos para análise de alimentos. (4th ed.). São Paulo: IAL, 2008. Brasília: Ministério da Saúde, 1020 p. Retirado de:

http://www.ial.sp.gov.br/resources/editorinplace/ial/20 16_3_19/analisedealimentosial_2008.pdf?attach=true.

[Acessado em: 03, Jan., 2019].

[18] Association of Official Analytical Chemists AOAC. Official methods of analysis of AOAC International. (17th ed.). Gaithersburg: (v. 1, p. 12.1-12.3., v.2, p.33. 1-33.88). AOAC, 2003.

[19] 3M do Brasil. Petrifilm ${ }^{\text {TM }}$. Guia de interpretação. Placas Petrifilm ${ }^{\text {TM }}$ Staph Express para contagem expressa de Staphylococcus aureus. 3M Microbiologia, 3M do Brasil Ltda. Disponível em: http://multimedia.3m.com/mws/media/5868600/guiaplaca-petri-staph-

express.pdf?\&fn=PetrifilmStaphExpressSTX.pdf.

[Acessado em: 18, Fev., 2019].

[20] American Public Health Association - APHA. Compendium of methods for the microbiological examination of foods. (4th ed.). Washington: APHA. 2001.

[21] Bligh EG, Dyer WJ. A rapid method of total lipid extraction and purification. Can. J. Biochem. Physiol. 1959;37(8):911-917.

[22] Atwater WO. Principles of nutrition and nutritive value of food. (Farmers' Bulletin 142). Washington: Government Printing Office, US Department of Agriculture. 141 p. 1910. (Corrected to April 20, 1910; reprinted without change, January, 1916). Retirado de: https://ia800301.us.archive.org/15/items/principlesofnu tr00atwa/principlesofnutr00atwa.pdf. [Acessado em: 02, Jan., 2019].

[23] R Core Team. R: A language and environment for statistical computing. $\mathrm{R}$ Foundation for Statistical Computing, Vienna, Austria, 2018.

[24] Medeiros LB, Saccol ALF, Delevati MTS, Brasil CCB. Diagnóstico das condições higiênicas de serviços de alimentação de acordo com a NBR 15635:2008. Braz. J. Food Technol. 2012;15(no.spe):47-52.

[25] Halpin-Dohnalek MI, Marth EH. Growth and production of enterotoxin A by Staphylococcus aureus in cream. J. dairy sci. 1989;72(9):2266-2275. 
[26] Rodrigues MSA, Deodato JNV, Lima FF, Martins WF, Almeida MCBM, Araújo AS. Estudo das condições higienico-sanitárias e físico-químicas de sorvetes sabores chocolate e morango comercializados em Pombal-PB. Hig. aliment. 2011;25:923-925.

[27] Jadhav AS, Raut PD. Evaluation of microbiological quality of ice creams marketed in Kolhapur city, Maharashtra, India. Int.J.Curr.Microbiol.App.Sci. 2014;3(9):78-84.

[28] Kokkinakis EN, Fragkiadakis GA, Ioakeimidi SH, Giankoulof IB, Kokkinaki AN. Microbiological quality of ice cream after HACCP implementation: a factory case study. Czech J. Food Sci. 2008;26(5):383-391.

[29] White HJ, Vilela DC, Krepp ACM, Goulart RMQC. Análise microbiológica das mãos dos manipuladores envolvidos no preparo de dietas enterais do hospital de Itajubá, MG. Nutr. Pauta. 2005;70(3):46-49.

[30] Oliveira ET, Batista PJS, Oliveira EG, Silva ITF, Froehlich Â. Avaliação Microbiológica de Sorvetes Comercializados nos Principais Supermercados de Maceió-AL. VII Congresso de Pesquisa e Inovação da Rede Norte e Nordeste de Educação Tecnológica - VII CONNEPI. (Ciência, tecnologia e inovação: ações sustentáveis para o desenvolvimento regional), Palmas Tocantins, 2012. Retirado de: http://propi.ifto.edu.br/ocs/index.php/connepi/vii/pap er/view/5505/3071. [Acessado em: 03, Jan., 2019].

[31] Siqueira RS. Manual de microbiologia de alimentos. Brasília, DF: Embrapa-SPI; Rio de Janeiro: EmbrapaCTAA, 1995. 159 p.

[32] Pazianotti L, Bosso AA, Cardoso S, Costa MR, Sivieri K. Características microbiológicas e físicoquímicas de sorvetes artesanais e industriais comercializados na região de arapongas-PR. Rev. Inst. Latic. “Cândido Tostes”. 2010;65(377):15-20.

[33] Brasil, Agência Nacional de Vigilância Sanitária (ANVISA). Regulamento técnico referente a gelados comestíveis, preparados, pós para o preparo e bases para gelados comestíveis. (Portaria $\mathrm{n}^{\mathrm{o}} 379$, de 26 de abril de 1999). Diário Oficial da União, Brasília, DF, 29 de abril de 1999.1 Retirado de: http://bvsms.saude.gov.br/bvs/saudelegis/svs1/1999/p rt0379_26_04_1999.html. [Acessado em: 05, Jan., 2019].

[34] Brasil. Ministério da Saúde. Agência Nacional de Vigilância Sanitária (ANVISA). (2003, dezembro 23). Aprova o regulamento técnico de porções de alimentos embalados para fins de rotulagem nutricional (Resolução RDC no 359, de 23 de dezembro de 2003). Diário Oficial [da] República Federativa do Brasil, Brasilia, DF, 26 de dezembro de 2003. Seção 1. Retirado de: http://bvsms.saude.gov.br/bvs/saudelegis/anvisa/2003 /anexo/anexo_res0359_23_12_2003.pdf. [Acessado em: 02, Jan., 2019].

[35] Suzuki RM. Composição Química e Quantificação de Ácidos Graxos em chocolates, achocolatados em pó, bebidas achocolatadas e sorvetes de chocolate. Tese (Doutor em Ciências) - Departamento de Química, Universidade Estadual de Maringá, Maringá, 2009. 114 f.

[36] Passos AAC, Teixeira-Sá DMA, Morais GMD, Chacon LSS, Braga RC. Avaliação da incorporação de galactomanana de Caesalpinia pulcherrima em sorvetes e comparação com estabilizantes comerciais. Rev. Ciênc. Agron. 2016;47(2):275-282.

[37] Ramos AF. Avaliação de aspectos físico-químicos, sensoriais e reológicos de sorvete gourmet elaborado com teor reduzido de lactose. Dissertação (Mestre em Ciência e Tecnologia do Leite e Derivados) - Mestrado Profissional em Ciência e Tecnologia do Leite e Derivados, da Universidade Federal de Juiz de Fora. Juiz de Fora, 2016. 66f.

[38] Félix LD, Alves JEA, Oliveira CA. Caracterização fisíco-química de sorvetes industrializados e comercializados na região de Salgueiro-PE. I Congresso Internacional das Ciências Agrárias. COINTER PDVAgro - Formação de Rede de Cooperação nas Ciências Agrárias. (00097), (DOI: 10.31692/2526-7701). IFPE Campus Vitória de Santo Antão - PE, 2016. Retirado de: https://cointer-pdvagro.com.br/wpcontent/uploads/2016/12/CARACTERIZA $\%$ C3\%87\% C3\%83O-FIS $\%$ C3\%8DCO-QU $\%$ C3\%8DMICA-DESORVETES-INDUSTRIALIZADOS-ECOMERCIALIZADOS-NA-REGI\%C3\%83O-DESALGUEIRO-PE.pdf. [Acessado em: 06, Jan., 2019].

[39] Franco BDGM, Landgraf M. Microbiologia dos alimentos. (1 th ed.). São Paulo: Atheneu, 2005. 196p. 